\section{Bacopa monnieri, a Neuroprotective Lead in Alzheimer Disease: A Review on Its Properties, Mechanisms of Action, and Preclinical and Clinical Studies}

\author{
Aimi Syamima Abdul Manap1, Shantini Vijayabalan², Priya \\ Madhavan ${ }^{3} \mathbb{D}$, Yoke Yin Chia', Aditya Arya $^{3}$, Eng Hwa Wong ${ }^{3}$, \\ Farzana Rizwan ${ }^{3}$, Umesh Bindal ${ }^{3}$ and Shajan Koshy ${ }^{3}$ \\ ${ }^{1}$ School of Biosciences, Faculty of Health and Medical Sciences, Taylor's University, Subang \\ Jaya, Malaysia. ${ }^{2}$ School of Pharmacy, Faculty of Health and Medical Sciences, Taylor's \\ University, Subang Jaya, Malaysia. ${ }^{3}$ School of Medicine, Faculty of Health and Medical \\ Sciences, Taylor's University, Subang Jaya, Malaysia.
}

Drug Target Insights Volume 13: 1-13

(C) The Author(s) 2019

Article reuse guidelines:

sagepub.com/journals-permissions

DOI: $10.1177 / 1177392819866412$

(S)AGE

\begin{abstract}
Alzheimer disease is a neurodegenerative disease that is signified by cognitive decline, memory loss, and erratic behavior. Till date, no cure for Alzheimer exists and the current Alzheimer medications have limited effectiveness. However, herbal medicines may slow down the disease's progression, which may hopefully reduce the number of cases in the years to come. Numerous studies have been done on characterizing the neuroprotective properties from plants belonging to Scrophulariaceae family, particularly Bacopa monnieriand its polyphenolic compounds known as bacosides. This review presents the findings on bacosides in therapeutic plants and their impact on Alzheimer disease pathology. These reports present data on the clinical, cellular activities, phytochemistry, and biological applications that may be used in new drug treatment for Alzheimer disease.
\end{abstract}

KEYWORDS: Alzheimer, aging, therapeutic plant, Bacopa monnieri, bacosides

RECEIVED: July 5, 2019. ACCEPTED: July 8, 2019.

\section{TYPE: Review}

FUNDING: The author(s) disclosed receipt of the following financial support for the research, authorship, and/or publication of this article: This study was supported by Taylor's University Flagship Research Grant (TUFR/2017/002/04).
DECLARATION OF CONFLICTING INTERESTS: The author(s) declared no potential conflicts of interest with respect to the research, authorship, and/or publication of this article.

CORRESPONDING AUTHOR: Priya Madhavan, School of Medicine, Faculty of Health and Medical Sciences, Taylor's University, Lakeside Campus, No. 1 Jalan Taylor's, 47500 Subang Jaya, Selangor Darul Ehsan, Malaysia. Email: priya.madhavan@taylors.edu.my
Alzheimer disease $(\mathrm{AD})$ is a devastating, progressive, and irreversible neurodegenerative disorder, which is clinically characterized by the deterioration of memory, disorientation, increased confusion, and other psychological as well as physical manifestations (Figure 1). ${ }^{1}$ The appearance of extracellular amyloid-beta $(A \beta)$ deposits in senile plaques and the development of intracellular neurofibrillary tangles, reactive microgliosis, and astrogliosis are the primary histopathological characteristics of AD. ${ }^{2}$ Alzheimer disease primarily affects the elderly, ${ }^{3}$ is the most common and feared type of dementia, represents $70 \%$ of all dementia cases, and is a worldwide epidemic. Bertram et $\mathrm{al}^{4}$ postulated that in addition to the sporadic form of $\mathrm{AD}$, for which aging is the primary factor, mutations in the amyloid-beta precursor protein (A $\beta P P)$, presenilin 1 (PSEN1), and presenilin 2 (PSEN2) cause autosomal dominant earlyonset familial AD. Polidori et $\mathrm{al}^{5}$ found that genetic and environmental factors, vascular pathology, and other risk factors also play crucial roles in $\mathrm{AD}$ pathogenesis.

Due to the lack of effective disease-modifying treatments, findings on pharmacological or nonpharmacological strategies to slow disease progression are of significant importance. In addition, the failure of potential pharmaceuticals in human clinical trials has highlighted the need for research into early $\mathrm{AD}$ diagnosis. As synaptic and neuronal loss along with brain shrinkage has already occurred when AD's clinical symptoms appear, current treatments that seek to slow disease progress are more likely to be effective before the onset of AD symptoms, ideally at the earliest preclinical stage. The lack of effective $\mathrm{AD}$ treatments and pharmaceuticals has led to the assessment of alternative therapeutics, such as nutraceuticals. For example, many antioxidants may enhance cognitive ability. ${ }^{6-8}$ Nutraceuticals have an effect on various neurodegenerative diseases as they modulate signaling pathways. ${ }^{9}$ Nutraceuticals are nutrients, herbals, and dietary supplements that can help in maintaining physical wellbeing, work against various diseases, and ensure a better quality of life. Bacosides from Bacopa monnieri ( $B$ monnieri) are examples of valuable therapeutic agent for $\mathrm{AD}$ due to their anti-inflammatory, antioxidant, and $\mathrm{A} \beta$ aggregation inhibitor properties. This review presents current clinical studies and scientific evidences that document the therapeutic potential of $B$ monnieri extracts (BME) such as bacosides in AD.

\section{Traditional Aspects of $B$ monnieri}

According to World Health Organization, traditional medicine is defined as "the sum total of knowledge, skills and practices based on the theories, beliefs and experiences of different cultures that are used to maintain health, as well as to prevent, diagnose, improve or treat physical and mental illnesses." 10 Many population in the developing countries have reverted to the use of traditional plants in maintaining their health and wellbeing. ${ }^{11}$ In this age where migration has taken a leap, immigrants tend to bring traditional plants from their country of origin to use as supplements. This has caused the promotion 


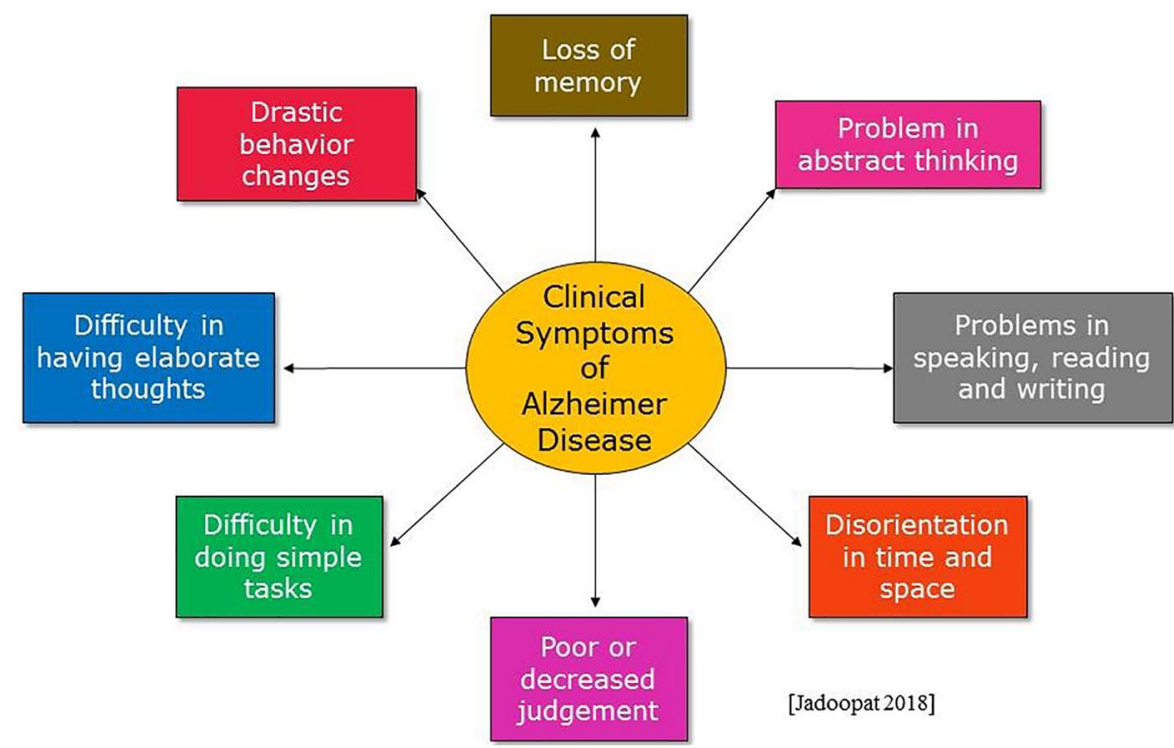

Figure 1. Clinical symptoms of Alzheimer disease.

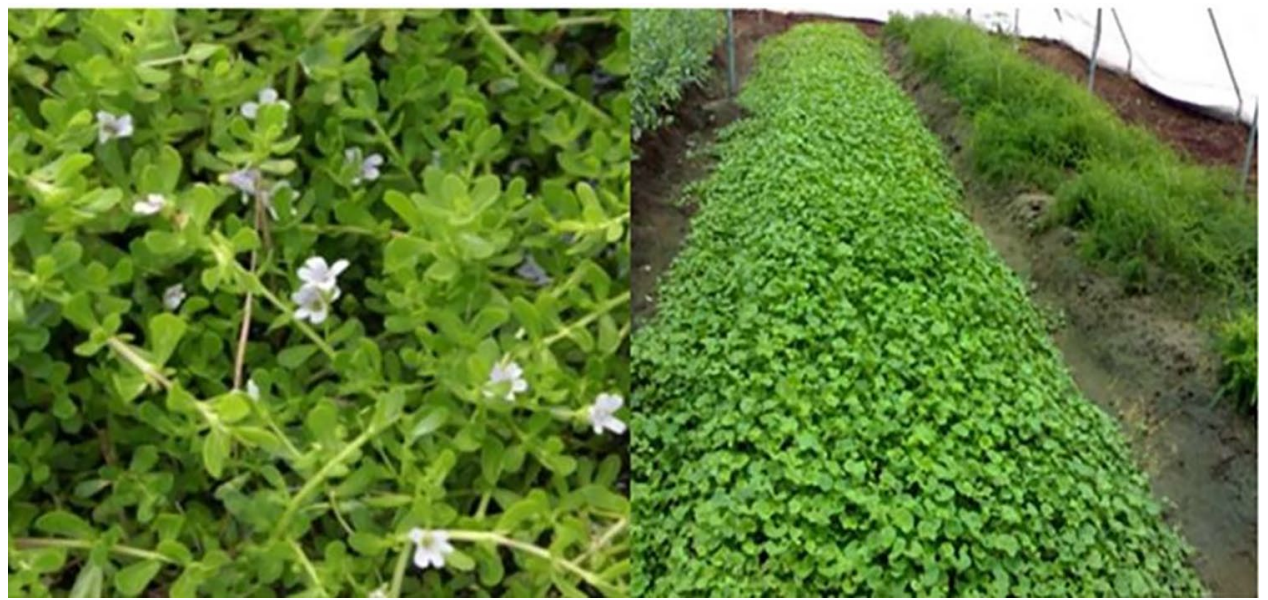

Figure 2. Bacopa monnieri plants.

of such non-native plants in a foreign country, particularly the ones used in Ayurvedic and Chinese traditional medicine. ${ }^{12}$ These plants or plant compounds are known as complementary or alternative medicines in non-native countries. Notably, $B$ monnieri, otherwise known as Brahmi and Aindri (Sanskrit) is classified into the Scrophulariaceae family and found throughout the Indian subcontinent in moist soil, humid, and muddy environments. ${ }^{13}$ The genus Bacopa has 146 aquatic herbal species dispersed throughout the subtropical regions of the globe, including Nepal, India, Sri Lanka, Taiwan, China, and Vietnam, as well as Florida and other US southern regions. Although it can be seen in the United States, these plants are perceived as weeds in rice fields and abundantly grown in wetlands and marshes of warmer districts. ${ }^{14}$ As shown in Figure 2, Brahmi is a succulent herb commonly grown in subtropical nations up to $1500 \mathrm{~m}$ altitude. Brahmi, which is traditionally known as "medhya rasayana," which means brain tonic or nootropic, or in Sanskrit word, referring to intellectual, cognition, and rejuvenation because it enhances the brain's cognitive properties, is popular among Ayurveda practitioners, who use it to treat various ailments, (ie, memory loss, inflammation, epilepsy, fever, and asthma). ${ }^{15}$

\section{Structure and Components of Bacosides}

The chemical compound that has neuropharmacological properties and pseudo-jujubogenin moieties, known as aglycone units, is Bacoside A (dammarane-type triterpenoid saponin; Figure 3). ${ }^{16,17}$ This compound is composed of bacopaside III, bacopaside X, bacoside A3, and bacopasaponin C. ${ }^{15}$ Through structural similitude analysis, 12 analogues derived from the bacosides have been characterized and various saponin types have been identified as essential ingredients, known as bacopasides I-XII. ${ }^{18}$ Bacopa's additional components include apigenin, cucurbitacin, alkaloids brahmine, monnierin, hersaponin, monnierasides I-III, plantain side $\mathrm{B}$, D-mannitol, herpestine, and nicotine. ${ }^{19,20}$ Table 1 shows molecular composition of Bacoside A. 


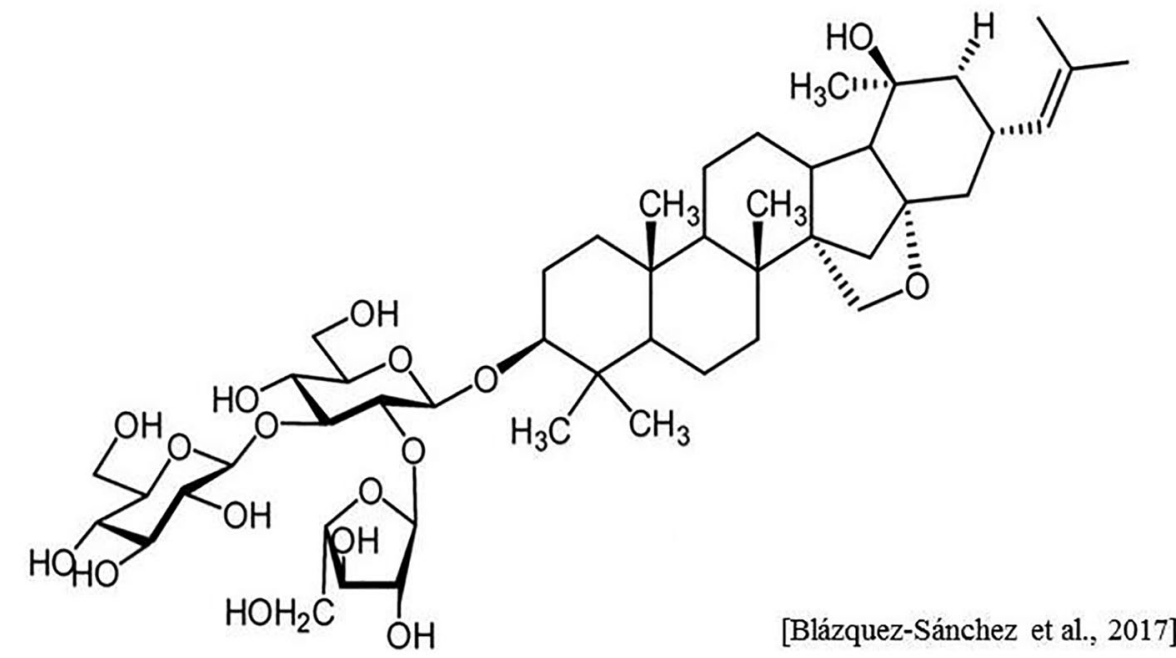

Figure 3. Chemical structure of Bacoside A. ${ }^{1}$

\section{The Neuropharmacological Activity of Bacoside A}

Numerous studies suggested that $B$ monnieri's bioactive components (ie, bacosides) protect the brain against oxidative damage and age-related cognitive deterioration with several mechanisms of action. ${ }^{22,23}$ In addition, bacosides prevent $A ß$ aggregation and formation of fibrils ${ }^{24}$ as well as protect neurons against $A \beta$-induced toxicity. ${ }^{25}$ From high-performance liquid chromatography (HPLC) analysis, the bioactive constituent, bacoside $\mathrm{A}$, was present in the $B$ monnieri extract (BME)treated rat serum and could directly or indirectly interact with the neurotransmitter systems to improve memory and learning ability. ${ }^{26}$ Bacosides present in $B$ monnieri are commonly nonpolar glycosides, ${ }^{27}$ which enable it to cross the blood-brain barrier $(\mathrm{BBB})$ via simple lipid-mediated passive diffusion. ${ }^{28}$ Similarly, the bioavailability in the brain has been affirmed by the radiopharmaceuticals biodistribution. ${ }^{29}$ De et al, using an animal model, described BME as being capable of altering the uptake of radioactivity of ${ }^{99} \mathrm{~m} T \mathrm{~T}-$ labeled ethylene dicysteine

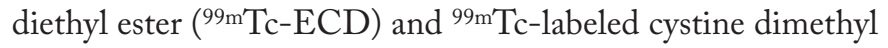
ester $\left({ }^{99} \mathrm{~m} \mathrm{Tc}-\mathrm{CDM}\right)$ in brain and other organs. The results revealed an increased and significant uptake $(P<.05)$ of ${ }^{99 \mathrm{~m} T \mathrm{c}-}$ ECD and ${ }^{99} \mathrm{~m}$ Tc-CDM in brain and other organs after treatment with BME. As BME is a good antioxidant and has cognitive function on human memory, these findings have evaluated pharmacokinetic interactions of BME and suggested that BME can act on the biodistribution of ${ }^{99} \mathrm{~m} T \mathrm{c}-\mathrm{ECD}$ and

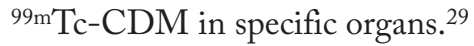

Likewise, clinical studies also showed that oral treatment with $B$ monnieri was able to enhance memory in both adults and children. The effects of $B$ monnieri administration on hepatic and intestinal P-glycoprotein (Pgp) as well as Cytochrome 3A (CYP3A) expression levels were examined in Watkins' studies. ${ }^{30}$ According to him, individually, Pgpmediated efflux and Cytochrome P450 (CYP45O)-mediated metabolism play a vital role in modulating the oral bioavailability of corresponding drug. However, $B$ monnieri mediating effects on CYP3A4 and alterations in Pgp were measured according to the mRNA expression level and functional activity in the intestine and liver of male Sprague Dawley (SD) rats after a week of $B$. monnieri administration. The results showed that B. monnieri downregulated both intestinal Pgp and CYP3A expression levels, depending on the testosterone hydroxylase catalytic activity in liver and intestine. ${ }^{31}$ Further studies also showed that in vivo pharmacokinetic interaction between digoxin (Pgp substrate) and carbamazepine (CYP 3A substrate) along with the administration of $B$ monnieri extract in male $\mathrm{SD}$ rats could alter the pharmacokinetics of both Pgp and CYP3A probe drugs. Probe drug is known to lessen both biological and technical risk factors of tracking a particular target to be selective as well as potent to their target. The results showed that treatment with $B$ monnieri and carbamazepine caused a change in the carbamazepine pharmacokinetic profile with a significant increase in $\mathrm{Cmax}$ (maximum serum concentration of the drug achieved in the plasma) and AUC (the area under the plasma drug concentration-time curve) $(0-\infty)$ as well reduction in $\mathrm{CL} / \mathrm{F}$ (apparent total clearance of the drug from plasma after oral administration) opposing to the vehicle control rats.

\section{The Role of Other Compounds in BME CDR1-08}

Also known as Synapsa, or KeenMind, a nootropic CDR1-08 is a well-characterized ethanolic extract of $B$ monnieri. Several lines of evidence demonstrated that CDRI-08 significantly enhances the cognitive performance in the elderly and patients with impaired neurological functions $s^{32-34}$ as well as healthy human participants. ${ }^{35,36}$ Moreover, bacosides present in the CDRI-08 are nonpolar glycosides, and it can enter the brain by crossing the $\mathrm{BBB}$ through lipid-mediated passive diffusion. ${ }^{28}$ The biodistribution in brain also has been affirmed by radiopharmaceuticals. ${ }^{29}$ Study by Preethi et al investigated whether treatment with the CDRI-08 could change the methylation 
Table 1. Molecular composition of Bacoside- $\mathrm{A}^{21}$.

\begin{tabular}{|c|c|}
\hline COMPOSITION & FUNCTIONAL UNIT \\
\hline Bacopaside & $\begin{array}{l}\text { 3-O- } \alpha \text {-L-arabinofuranosyl-( } 1 \rightarrow 2) \text {-[6-O-sulfonyl- } \beta \text {-D-glucopyranosyl-( }(1 \rightarrow 3)]-\alpha \text {-L-arabinopyranoside, 3-O-ß-D- } \\
\text { glucopyranosyl-(1 } \rightarrow 3) \text { - } \alpha \text {-L-arabinofuranosyl }\end{array}$ \\
\hline Bacopaside V & $\begin{array}{l}\text { 3-O- } \alpha \text {-L-arabinofuranosyl-( }(1 \rightarrow 2) \text {-[6-O-sulfonyl- } \beta \text {-D-glucopyranosyl-( } 1 \rightarrow 3)]-\alpha-L \text {-arabinopyranoside, 3-O-ß-D- } \\
\text { glucopyranosyl-(1 } \rightarrow 3 \text { - } \alpha \text {-L-arabinofuranosyl }\end{array}$ \\
\hline Bacopaside II & 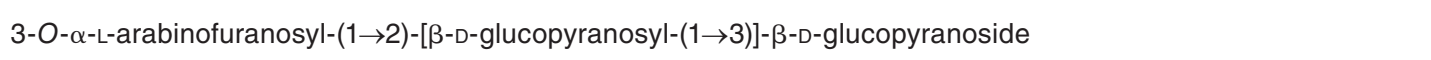 \\
\hline Bacopaside III & 3-O-(6-O-sulfonyl- $\beta$-D-glucopyranosyl-[1 $\rightarrow 3])-\alpha$-L-arabinopyranoside \\
\hline \multirow[t]{2}{*}{ Bacopaside IV } & 3-O-ß-D-glucopyranosyl-(1 $\rightarrow 3)-\alpha$-L-arabinopyranosyl \\
\hline & 3-O-\{ß-D-glucopyranosyl(1 $\rightarrow 4)(\alpha-L-a r a b i n o f u r a n o s y l-[1 \rightarrow 2])-B-D-g l u c o p y r a n o s y l\}-20-O-\alpha-L-a r a b i n o p y r a n o s y l$ \\
\hline Bacopaside IX & $\begin{array}{l}\text { 3-O-ß-D-glucopyranosyl-(1 } \rightarrow 3)-\alpha \text {-L-arabinopyranosyl } \\
\text { 3-O-\{ß-D-glucopyranosyl }(1 \rightarrow 4)(\alpha \text {-L-arabinofuranosyl-[1 } \rightarrow 2])-\beta \text {-D-glucopyranosyl\}-20-O- } \alpha \text {-L-arabinopyranosyl }\end{array}$ \\
\hline Bacopaside XI & 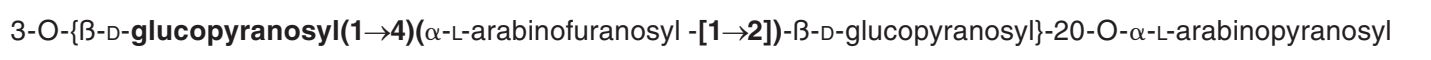 \\
\hline $\begin{array}{l}\text { Bacopaside } \\
\text { XII-12 }\end{array}$ & 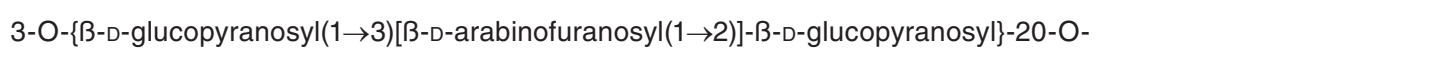 \\
\hline Bacopasaponin A & 3,20-di-O- $\alpha$-L-arabinopyranoside \\
\hline Bacoside $A_{1}$ & 3-O-( $\alpha$-L-arabinofuranosyl[1-3])- $\alpha$-L-arabinopyranoside \\
\hline Bacoside $A_{2}$ & 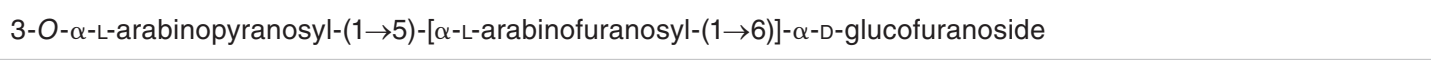 \\
\hline Bacoside $\mathrm{A}_{3}$ & 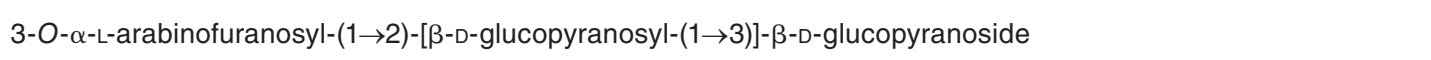 \\
\hline Bacopasaponin B & 3-O-( $\alpha$-L-arabinofuranosyl-[1-2])- $\alpha$-L-arabinopyranoside \\
\hline Bacopasaponin C & 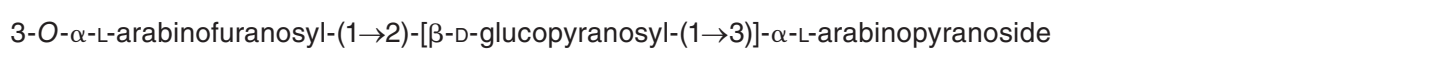 \\
\hline Bacopasaponin D & 3-O-( $\alpha$-L-arabinofuranosyl-[1-2])- $\beta$-D-glucopyranoside \\
\hline Bacopasaponin E & 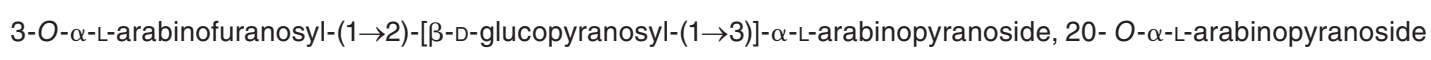 \\
\hline Bacopasaponin F & 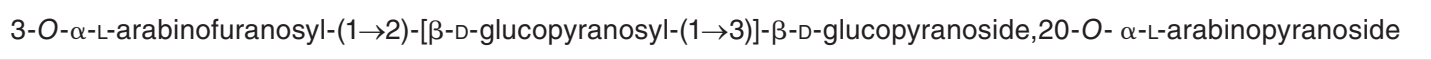 \\
\hline $\begin{array}{l}\text { Bacopasaponin } \\
\text { G }\end{array}$ & 3-O-( $\alpha$-L-arabinofuranosyl-[1-2])- $\alpha$-L-arabinopyranoside \\
\hline Bacopasaponin H & 3-O-[ $\alpha$-L-arabinopyranosyl] \\
\hline
\end{tabular}

status of reelin and brain-derived neurotrophic factor (BDNF) to enhance the memory through the interaction of $N$-methylD-aspartate receptor (NMDAR) with synaptic proteins. Using rat pups as a model in the study, after treatment with CDR108/5-azacytidine $(80 \mathrm{mg} / \mathrm{kg} / 3.2 \mathrm{mg} / \mathrm{kg})$, their results demonstrate a higher discrimination toward novel objects than with old objects during the testing. They also observed an elevated level of unmethylated DNA in reelin and BDNF-promoted region, which suggested that this mechanism might contribute to the modulation of synaptic plasticity and thus can enhance learning and memory. ${ }^{37}$ However, study by Rai et al provides the evidence for the mechanism underlying the role of the CDRI-08 in restoring spatial memory in amnesic mice. In their study, upon daily oral administration of CDRI-08 ( $200 \mathrm{mg} / \mathrm{kg}$ body weight [BW]) to scopolamine-treated amnesic mice for 7 days, the spatial memory was restored, which was found to be related with significant upregulation of the GluN2B (ionotropic glutamate receptors) subunit expression and reduction in the acetylcholinesterase activity in prefrontal cortex as well as hippocampus. ${ }^{38}$

\section{Bacognize ${ }^{\circledR}$}

The standardized extract of $B$ monnieri (Bacognize) has been shown to improve some aspects of cognitive functions in a 6-month trial in geriatric Alzheimer patients. ${ }^{39}$ In this study, all patients who took $300 \mathrm{mg}$ of Bacognize orally twice a day showed a statistically significant improvement in various components of Mini-Mental State Examination Scale (MMSES) including orientation of time, place and person, 


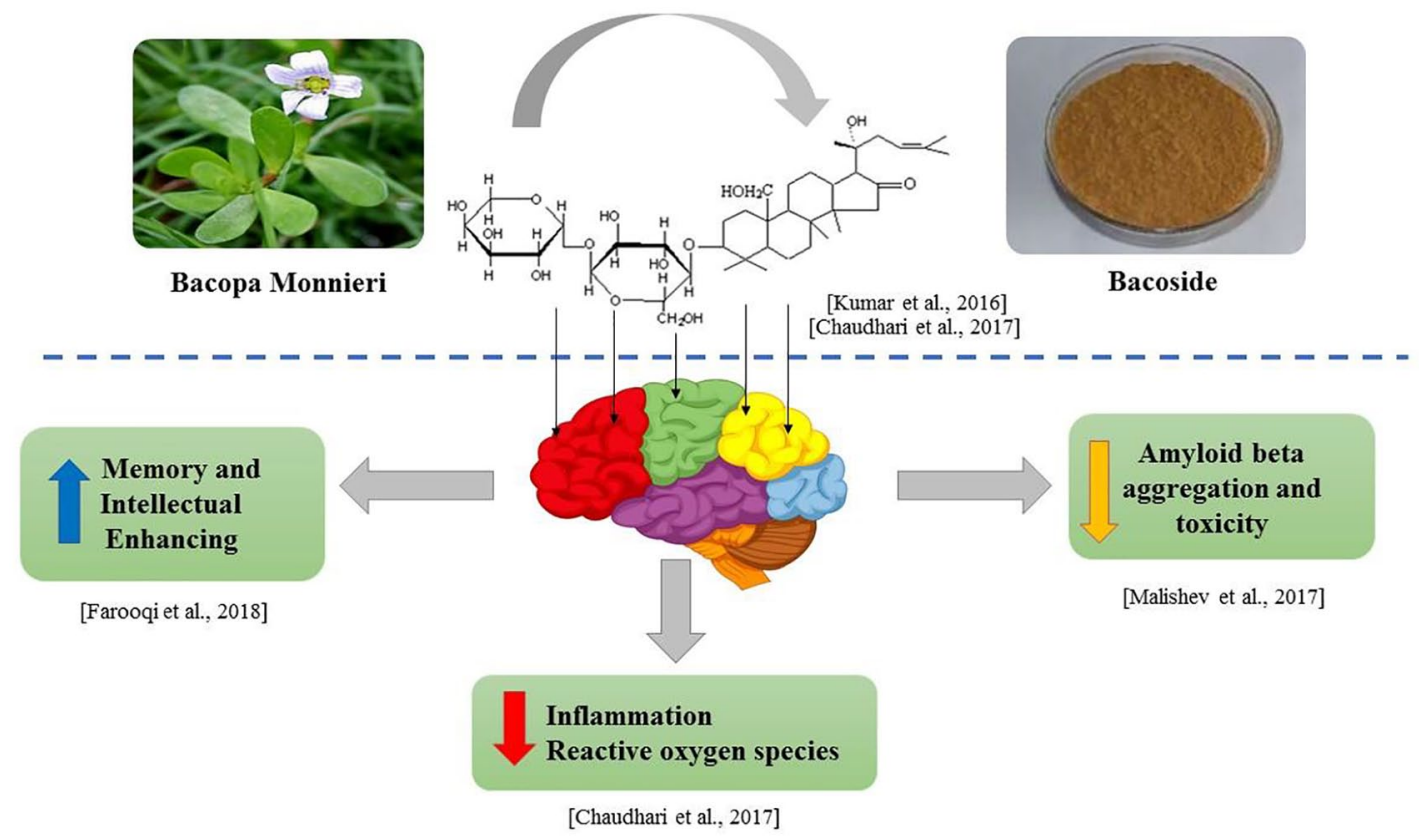

Figure 4. Neuroprotective effects of bacoside from Bacopa monnieri.

attention, and their language ability in terms of reading, writing, and comprehension at the end of trial. Another study refers this extract to be safe and have sustained cognitive effects when used for 12 weeks in healthy older adults. ${ }^{40}$ Kumar et al had evaluated the effect of Bacognize on memory of 60 medical students with 42 days of administration. This randomized placebo-controlled trial exhibited a significant improvement in the tests relating to the cognitive functions in the participants who had taken $150 \mathrm{mg}$ of Bacognize. ${ }^{41}$ The poor solubility of Bacognize also has been improved by recent study of Thakkar et al using the inclusion complex of Bacognize (contained 16\% bacosides) and $\beta$-cyclodextrin prepared in different molar ratios of $B$ monnieri via co-precipitation method. The results revealed that the inclusion of complex at molar ratio of 1:4 can enhance threefold solubility and stability of $B$ monnier $i$ in inclusion complex. ${ }^{42}$

\section{Mechanisms as a Neuroprotective Agent}

The mechanisms that underlie the progression of neuronal degeneration are described in the following sections. Figure 4 illustrates the neuroprotective effects of bacoside from $B$ monnieri from various studies. ${ }^{43-45}$

\section{Bacosides and Reactive Oxygen Species}

Wide studies have reported the role of superoxide anion, hydroxyl radical, hydrogen peroxide, and nitric oxide in the oxidative stress-mediated neurodegeneration in AD. ${ }^{46,47}$ Neuronal lesions can activate microglia activation, which further generates excessive superoxide radicals. ${ }^{48}$ Thus, mitochondrial autophagy serves as a vital source of reactive oxygen species (ROS) production. ${ }^{49}$ As mitochondria functions as both the source and target of toxic ROS, mechanisms by which mitochondrial dysfunction leads to neuron degeneration in $\mathrm{AD}$ are believed to be associated with ROS generation, activation of mitochondrial permeability transition, excitotoxicity, impaired production of adenosine triphosphate, and altered calcium homeostasis. ${ }^{50}$ Various studies have shown an increased level of 4-hydroxynonenal, the byproduct of oxidative stress in the brain of $\mathrm{AD}$ patients. ${ }^{51,52} \mathrm{An}$ increased level of lipid peroxidation (LPO) marker has been reported as well. ${ }^{53,54}$ Besides that, iron-induced oxidative stress, as demonstrated by iron accumulation in the brain of $\mathrm{AD}$, is responsible for neurodegeneration in patients diagnosed with AD. ${ }^{55}$

Extensive studies have been performed on neuroprotection of $B$ monnieri against ROS. The administration of $B$ monnieri inhibited LPO especially in the hippocampus, prefrontal cortex, and striatum areas of the rat cerebrum. ${ }^{56}$ As for the rat's astrocytes, it significantly reduced the harm done by high concentrations of nitric oxide. ${ }^{57}$ Likewise, different reports recommended that bioactive components from $B$ monnieri can protect the brain against oxidative harm and improve cognitive capability via a few mechanisms. ${ }^{22,23}$ The enhanced cognitive capability was attributed to the free radical scavenging properties of the bacosides. Superoxide dismutase (SOD), heat shock protein 70 (Hsp70), and cytochrome P450 (CytP450) in the rat's cerebrum have critical role in both the production of ROS and scavenging activity. ${ }^{58}$ The detoxification and binding of free radical scavenging metal ions or increasing the antioxidant properties are the mechanisms involved in the neuroprotection from bacosides $25,34,58$ (Figure 5). It also reduces the formation of lipid peroxides, divalent metals, scavenging ROS, and restraining lipoxygenase action. As results indicated that ROS level had declined when neurons were treated with BME, we propose that it may control the intracellular oxidative stress. ${ }^{25}$ 


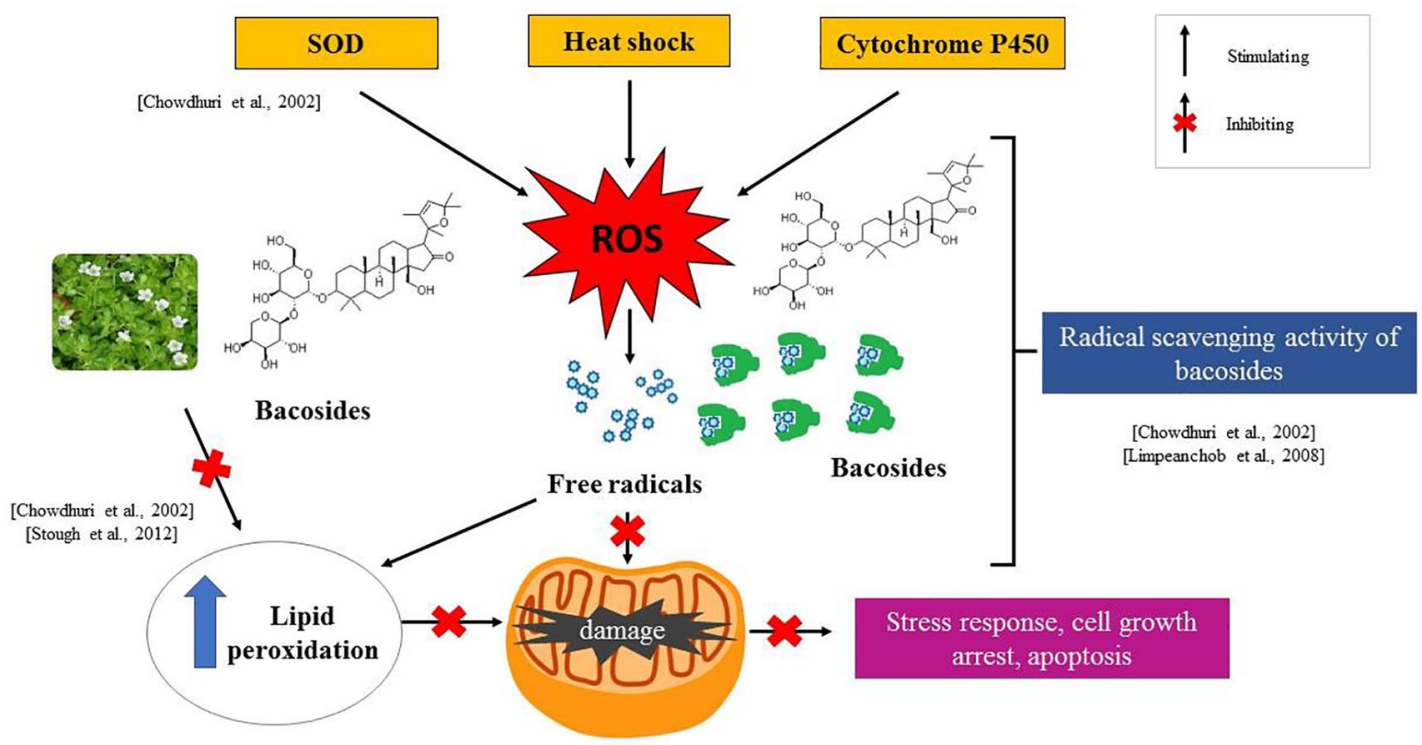

Figure 5. The action mechanism of bacoside against ROS induces mitochondrial damage. ROS indicates reactive oxygen species; SOD, superoxide dismutase.

Likewise, in neonatal hypoglycaemia, $B$ monnieri has potent neuroprotective capability in reversing the modified dopamine D1 receptor function, BAX (BCL2 Associated X, Apoptosis Regulator), and gene expressions, respectively. Thus, SOD level is lowered, which in turn causes cortical cell death. ${ }^{59}$

Furthermore, in rat models of neurotoxicity incitation by ibotenic corrosive and colchicine, $B$ monnieri indicated a dosage-related intellectual deficiencies. ${ }^{60}$ Acrolein is an exceptionally active compound shaped as a LPO byproduct and acts as an oxidative stress inducer by framing adducts of cell nucleophilic groups. It demonstrates a significant elevation of acrolein levels in the hippocampus; $B$ monnieri extract is accounted to have neuroprotection in human neuroblastoma cell line $\mathrm{SK}-\mathrm{N}-\mathrm{SH}$ against hydrogen peroxide and acrolein-induced toxicity. ${ }^{3}$ It also protects through ROS scavenging, maintains the mitochondrial membrane integrity, modulates the expression of several redox regulatory proteins, that is, Sirt1 (Sirtuin 1), NF- $\mathrm{B}$ (nuclear factor kappa-light-chain-enhancer of activated B cells), p66Shc (a member of the SHC family of protein adapters), and ERK1/2 (extracellular signal-regulated protein kinases 1 and 2), and protects the cells from oxidative stress. The counter pressure impact of bacosides of $B$ monnieri was studied in adult male $\mathrm{SD}$ rats. The results portrayed that it is able to de-stress the modulation of SOD, Hsp70, and CytP450 under unfavourable conditions, for example, stress. ${ }^{58}$

\section{Bacoside A and Beta Amyloid Toxicity}

A significant inhibitory effect of cytotoxicity, fibrillation, and membrane interactions of beta-amyloid (1-42) were observed by preincubation of Bacoside A with $\mathrm{A} \beta 42$ in $\mathrm{SH}-\mathrm{SY} 5 \mathrm{Y}$ cell line model. ${ }^{43} \mathrm{~A} \beta$ is a peptide that plays a prominent role in $\mathrm{AD}$ progression and toxicity. In $\mathrm{AD}, \mathrm{A} \beta$ assembles into insoluble amyloid fibrils that aggregate in extracellular neuritic or senile plaques $^{61,62}$ and is accompanied by synaptic dysfunction, neuronal deterioration, dementia, and cognitive declination. ${ }^{63}$

Therefore, it can suggest that $A \beta$ may be directly toxic to neuronal cells and synapses. The previous study showed that extracts containing soluble $A \beta$ aggregates can induce amyloidosis in an animal model that otherwise never develop amyloid plaque. ${ }^{64}$ Inhibition of $A \beta$ aggregates and assembly is one of the primary therapeutic strategies in $\mathrm{AD}$ treatment and prevention. Another study reported a substantial link between the toxic peptide of $A \beta$ with its membrane interaction. ${ }^{43}$ In their experiment, $A \beta 42$ monomer initially produces oligomeric species that were membrane-active and cytotoxic. It then aggregated into fibrils, which were promoted through interactions with the bilayer interface. However, aggregation of $A \beta 42$ was reduced and its membrane interaction was inhibited following incubation with Bacoside A. Figure 6 shows the mechanism of action of bacoside on $A \beta .{ }^{43,61}$

\section{Synergistic Action of $B$ monnieri}

The synergistic effects of $B$ monnieri have been investigated, providing information on its possible neuropharmacological effects between this herbal medicine and other plant extracts or synthetic drugs. The synergistic action of B monnieri $(320 \mathrm{mg})$, L-theanine $(100 \mathrm{mg})$, Crocus sativus $(30 \mathrm{mg})$, copper $(2 \mathrm{mg})$, folate $(400 \mu \mathrm{g})$ with vitamin B $(450-9 \mu \mathrm{g})$ and vitamin D $(25 \mu \mathrm{g})$ in a cohort of elderly subjects (1 capsule per day) for 8 weeks of treatment were investigated. ${ }^{66}$ The results showed a significant improvement of cognitive decline, perceived stress, and depression tested with Mini-Mental State Examination (MMSE), Perceived Stress Questionnaire (PSQ) Index, and Self-Rating Depression Scale (SRDS) scores.

In another study done in an in vivo model, combination of $B$ monnieri $(100 \mathrm{mg} / \mathrm{kg})$ with rivastigmine $(5 \mathrm{mg} / \mathrm{kg})$ showed significant protection against aluminum chloride $\left(\mathrm{AlCl}_{3}\right)$-induced 


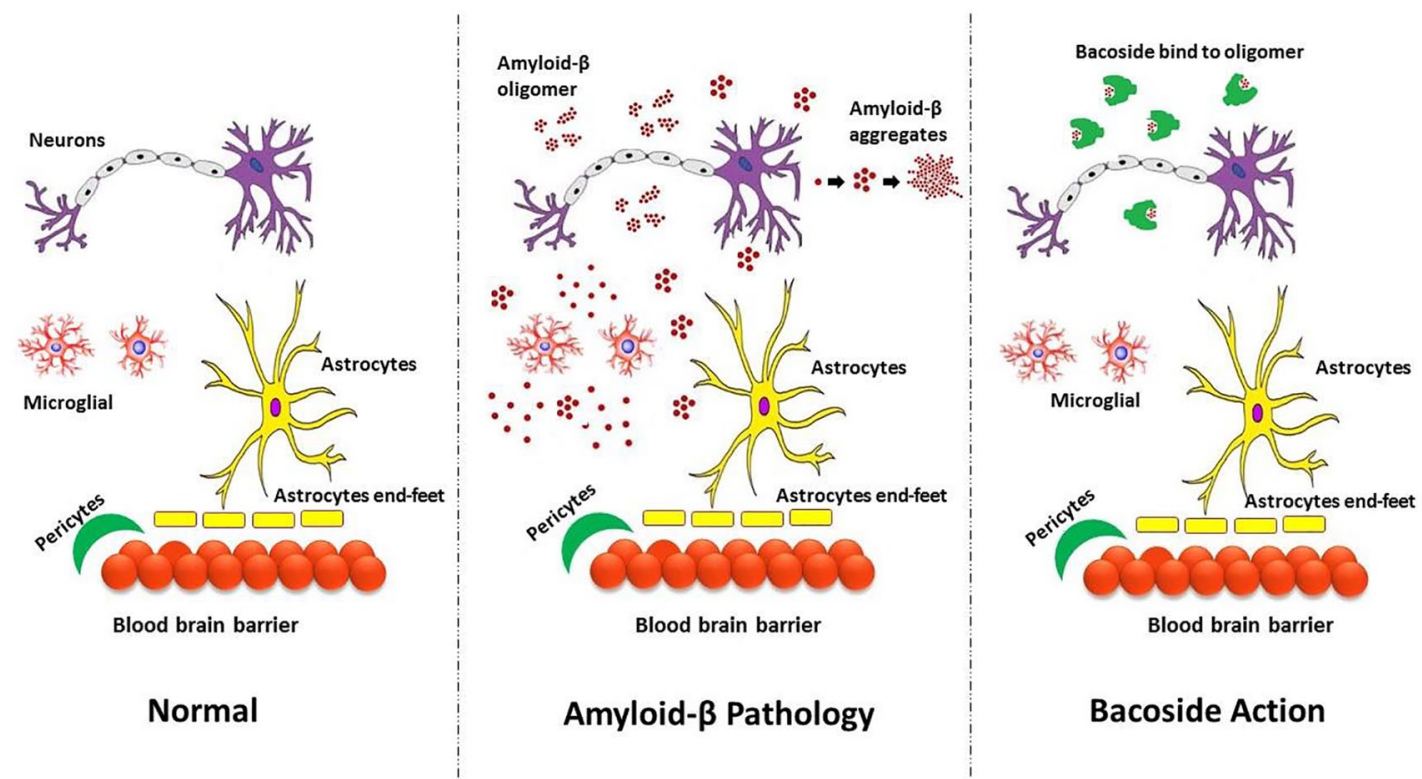

Figure 6. Mechanism of action of bacoside against beta-amyloid (adaptation and modifications from previous works ${ }^{2,3}$ ).

However, Bacoside A exhibited anti-amyloid toxicity properties upon membrane interactions and bilayer-induced fibrillation of pathogenic substance prion protein (PrP). The experimental data revealed that preincubation of PrP (106-126) with Bacoside A before addition to vesicle bilayers might possibly enhance fibril formation and in parallel had inhibited membrane interactions of the peptide assemblies. The findings from this study revealed a significant interaction of the compound with the amyloidogenic determinant of PrP and noticeable effects upon the structural and functional properties of the peptide even though Bacoside A has not been explored yet in conjunction with the prion protein. In a more extensive context, the anti-amyloid properties of Bacoside A might be discovered to its impact in ameliorating the amyloid protein toxicity via stimulating and enhancing fibrillation. 65

memory impairment in rats compared to those treated with $\mathrm{AlCl}_{3}$ per se. ${ }^{67}$ In their study, chronic administration of $\mathrm{AlCl}_{3}$ caused functional deficits in learning and memory skills, which were tested using the Morris water maze and Elevated Plus Maze (EPM) tasks. However, rats treated with combination of rivastigmine and $B$ monnieri showed better acquisition and retention latencies compared to groups treated only with $\mathrm{AlCl}_{3}$, indicating significant protection against $\mathrm{AlCl}_{3}$-induced deterioration in learning and memory skills. They concluded that $B$ monnieri and rivastigmine act through synergistic mechanisms to prevent neuronal damage and enhance cholinergic neurotransmission, thus showing better therapeutic effect compared to treatment alone.

Antidementia and anticholinesterase activities in adult male Swiss mice also were studied using combined extracts of $B$ monnieri and Ginkgo biloba (GB). ${ }^{68}$ In this study, anti-dementia activity was tested against scopolamine ( $3 \mathrm{mg} / \mathrm{kg}$ BW)-induced impairment in passive avoidance (PA) test. Their results indicate a significant increase in transfer latency time (TLT) and no transfer response (NTR) after treatment of combined extracts of $B$ monnieri at $30 \mathrm{mg} / \mathrm{kg}$ and $\mathrm{GB}$ at 15,30 , and $60 \mathrm{mg} / \mathrm{kg}$ for 7 days of administration. All the extracts showed potent effects toward attenuating the effects of dementia.

\section{In vivo and in vitro Study on Neuroprotective Effects of BME}

Research on neuroprotective effects of BME has been widely studied before by in vivo and in vitro models. Most of the study conducted by in vivo were performed on male Wistar rats and male Swiss albino mice and rats. However, for in vitro study, different cell line models were chosen to study the effect of BME such as PC12, SH-SY5Y, as well as primary cortical neuron cells. Uabundit et al demonstrated protective effects of $\mathrm{BME}$ in male Wistar rat model that had been induced with $2 \mathrm{nmol} / 2 \mu \mathrm{L}$ ethylcholine aziridinium ion (AF64A). Result showed that 20,40 , and $80 \mathrm{mg} / \mathrm{kg}$ BW of BME was able to mitigate the memory impairment and neurodegeneration in the rats by enhancing the escape latency time $(P<.01)$ in the Morris water maze test. They also observed that both cholinergic neuron and neuron density reduction were lessened. ${ }^{69}$ Other than that, BME administered orally at $40 \mathrm{mg} / \mathrm{kg} /$ day for 5 weeks was able to prevent the neurotoxicity in the cerebral cortex of male Wistar rat brain exposed with aluminum chloride $\left(\mathrm{AlCl}_{3}\right){ }^{70}$ Research done by Khan et al revealed that BME given orally at $30 \mathrm{mg} / \mathrm{kg}$ BW for 2 weeks significantly improved the memory and learning capability in intracerebroventricularstreptozotocin (ICV-STZ)-induced male Wistar rats. Their finding demonstrates the therapeutic efficacy of BME on cognitive impairment and oxidative damage, observed by significant reduction in LPO levels, increased GSH (glutathione) contents, and upregulated antioxidant enzymes activity such as SOD, GST (glutathione S-transferases), CAT (catalase), and GPx (glutathione peroxidase) in the hippocampus infused by ICV-STZ model. ${ }^{71}$ On a different study, BME at $100 \mathrm{mg} / \mathrm{kg}$ BW for 180 days lessened both the sodium nitrate $\left(\mathrm{NaNO}_{2}\right)$ and D-galactose (D-Gal) levels, which improved the BW, memory, and learning skills. $B$ monnieri extracts also normalized the ATPase system in AD-induced mice. ${ }^{72}$ Dwivedi et al ${ }^{73}$ 
also demonstrate attenuation of Okadoic acid (OKA)-induced memory dysfunction in SD rats treated with $\mathrm{BME}$ at 40 and $80 \mathrm{mg} / \mathrm{kg}$ BW for 13 days.

Moreover, interesting extensive finding by Rastogi et al revealed the protective effect of bacosides, against the age-associated neurodegeneration and promotion of healthy brain aging in female Wistar rats. In this study, bacosides were administered orally at $200 \mathrm{mg} / \mathrm{kg}$ BW for 3 months in middle aged and aged rats, and its impact on the prevention of Senile Dementia of Alzheimer Type (SDAT) was evaluated. Their findings demonstrated that bacosides was found to display significant anti-aging property by preventing the lipofuscin aggregation in the brain cortex of middle-aged and aged rat. Other than that, cholinergic neurotransmission was observed in aged-rat brain cortex, and treatment with bacosides was able to mitigate this age-associated cholinergic degeneration. Based on the potential findings on bacosides, they suggested that bacosides exerted multitargeted pharmacological action by preventing the lipofuscin accumulation, enhancing the synthesis of cholinergic neurotransmitter acetylcholine, modulating the metabolism of monoaminergic neurotransmitters, and inhibiting LPO in the aged rats. ${ }^{74}$

A previous study also investigated a new nanotechnology approach for the brain delivery of the Bacoside A for the treatment of neurodegenerative disorders using poly-(D, L)-Lactide-co-Glycolide (PLGA) as surfactant. Bacoside-A-loaded PLGA nanoparticles were prepared via oil-in-water $(\mathrm{o} / \mathrm{w})$ emulsion solvent evaporation technique. Surface of nanoparticles were modified by coating with polysorbate 80 to enhance the crossing of $\mathrm{BBB}$. The ability of nanoparticles in targeting the brain was evaluated by in vivo studies using Wistar albino rats. Their results suggested that PLGA nano Bacoside A formulation with a size range of $70-200 \mathrm{~nm}$ and a relatively low polydispersity index of $0.391 \pm 1.2$ showed encapsulation efficiency at $57.11 \% \pm 7.11 \%$, with a drug loading capacity of $20.5 \% \pm 1.98 \%$. Scanning electron microscopy (SEM) and $\mathrm{X}$-ray studies also revealed its spherical shape and low crystallinity. This verified that there were no chemical interactions between both polymer and drug molecules. The in vitro study showed a constant pattern with maximum release of $83.04 \% \pm 2.55 \%$ in 48 hours, while in vivo study showed a higher brain concentration of Bacoside A $(23.94 \pm 1.74 \mu \mathrm{g} / \mathrm{g}$ tissues) that implied a significant role of surface-coated nanoparticles on brain targeting. The overall results suggested the efficiency of surface-modified PLGA nanoparticles in delivery of Bacoside $\mathrm{A}$ to the brain. ${ }^{75}$

In vitro study demonstrated that scopolamine induced PC12 cell death was significantly ameliorated by BME pretreatment, and the viability was restored at $85.75 \%$ of the control with $100 \mu \mathrm{g} / \mathrm{mL}$ of BME. B monnieri extracts pretreated cells also showed a decreased release of lactate dehydrogenase (LDH) up to $22.42 \%$ of total as compared with $30 \%$ of scopolamine-treated group. $B$ monnieri extracts also found to ameliorate scopolamine effect by downregulating acetylcholinesterase
(AChE) and upregulating BDNF as well as muscarinic-1 receptor expression. ${ }^{76}$ While pretreatment of BME with different doses $(2.5-100 \mu \mathrm{g} / \mathrm{mL})$ for 3 hours in SK-N-SH cells prior to the addition of $200 \mu \mathrm{M}$ of $\mathrm{H}_{2} \mathrm{O}_{2}$ or $15 \mu \mathrm{M}$ of acrolein can significantly protect against acrolein-induced cytotoxicity. $B$ monnieri extracts also showed to inhibit the generation of intracellular ROS in addition to preserving the mitochondrial membrane potential. B monnieri extracts pretreatment also prevented the modifications caused by the activity of several redox regulated protein. ${ }^{3}$ Furthermore, Limpeanchob et al revealed the neuroprotective effect of BME against $A \beta$-induced cell death in primary cortical cultured neuron cells. They found that the cell viability of cultured cortical cells was increased when treated with $100 \mu \mathrm{g} / \mathrm{mL}$ of BME. From their study, they postulated that Brahmi extract can diminish neuronal death induced by $A \beta$ peptide through the suppression of $\mathrm{AChE}$ activity. Brahmi extract also exhibited antioxidant properties in both in vitro and cell-based assays. ${ }^{25}$ By using SH-SY5Y cell as a model, BME at 0.1 to $25 \mu \mathrm{M}$ significantly reduced neurotoxicity of oxidized low-density lipoprotein (LDL) in a dosedependent manner as well as suppressed the elevation of cellular AChE activity mediated by oxidized LDL. ${ }^{77}$ Using the same SH-SY5Y model, Bacoside A at $50 \mu \mathrm{M}$ exerted significant inhibitory effects upon cytotoxicity, fibrillation, and particularly membrane interactions of $A \beta(1-42)(A \beta 42) .{ }^{43}$ Table 2 outlines the specific effects of bacosides on various study designs (in vivo and in vitro) of AD.

\section{Clinical Studies in Humans Using BME}

Upon the promising neuroprotective effect of $B$ monnieri in in vitro and in vivo studies, numerous clinical studies on human subjects have been performed using $B$ monnieri for cognitive improvement. A clinical study of standardized extract of $B$ monnieri $(150 \mathrm{mg}$ ) on 60 medical students from Government Medical College, Nagpur, India over a period of 15 days revealed significant improvement in biochemical analyses, that is, significant elevation in serum calcium levels and enhanced memory test. ${ }^{41}$ Another group of researchers reported that individual doses of $B$ monnieri and Sideritis scardica extracts in 10 mild cognitive impairment subjects from Germany (mean age: $61.88 \pm 6.69$ years) resulted in improvement in the $\mathrm{d} 2$-concentration test. ${ }^{79}$ However, treatment with $B$ monnieri $(2 \times 150 \mathrm{mg})$ for 90 days in 107 participants (between ages 18 and 60years) in Swinburne University, Australia led to an improved performance in a structural working remembrance task in healthy participants with no history of neurological diseases, gastrointestinal disorders, as well as chronic infections. Above it all, none of the healthy participants took any cognitive-enhancing drugs. ${ }^{80}$

Besides cognitive improvement, $B$ monnieri can also enhance learning capability. Consumption of $B$ monnieri for 3 months in 76 human subjects between 40 and 65 years of age in University of Wollongong, Australia resulted in significant effects on retention of new information. ${ }^{81}$ The consistent consumption of 


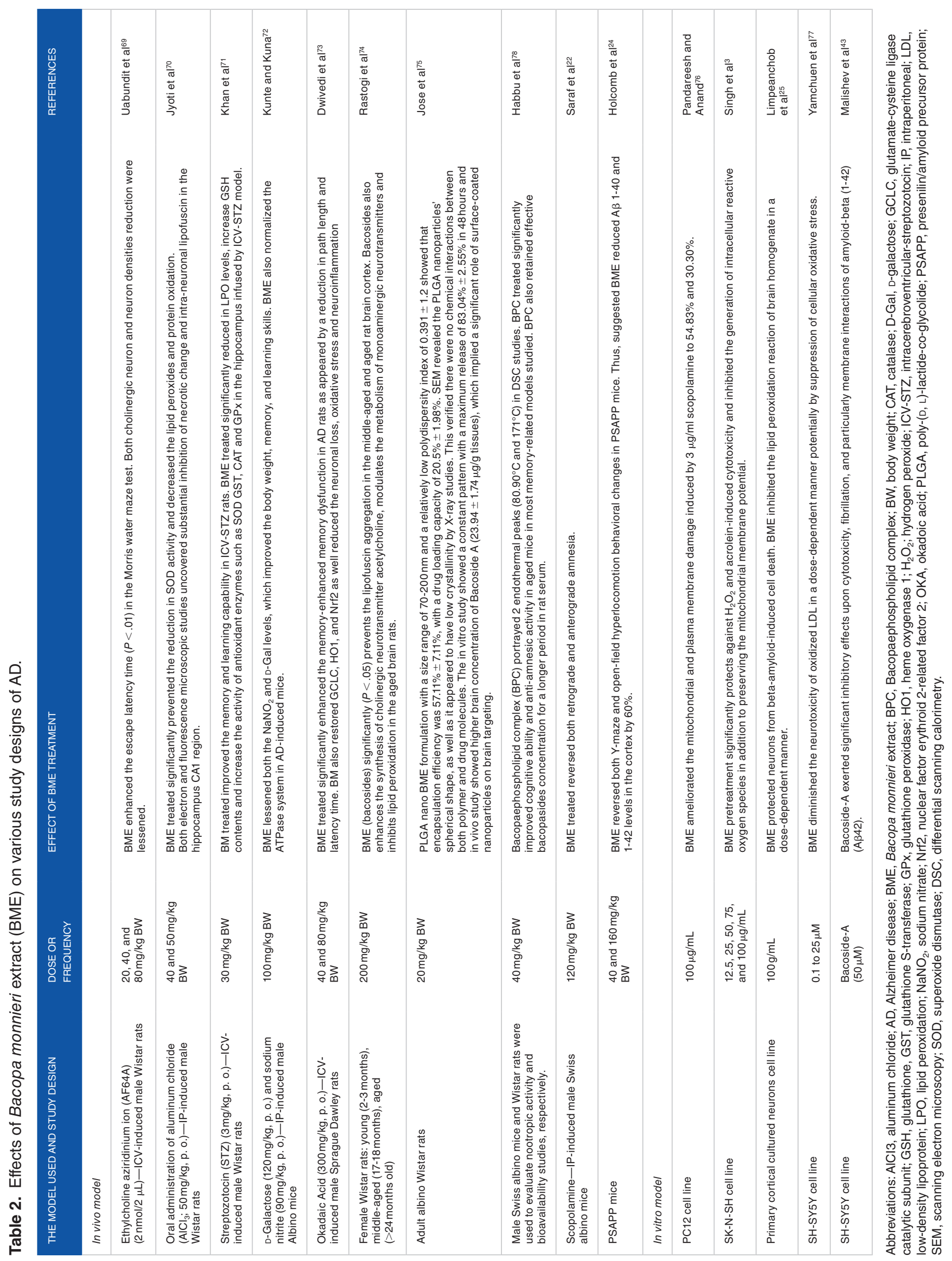




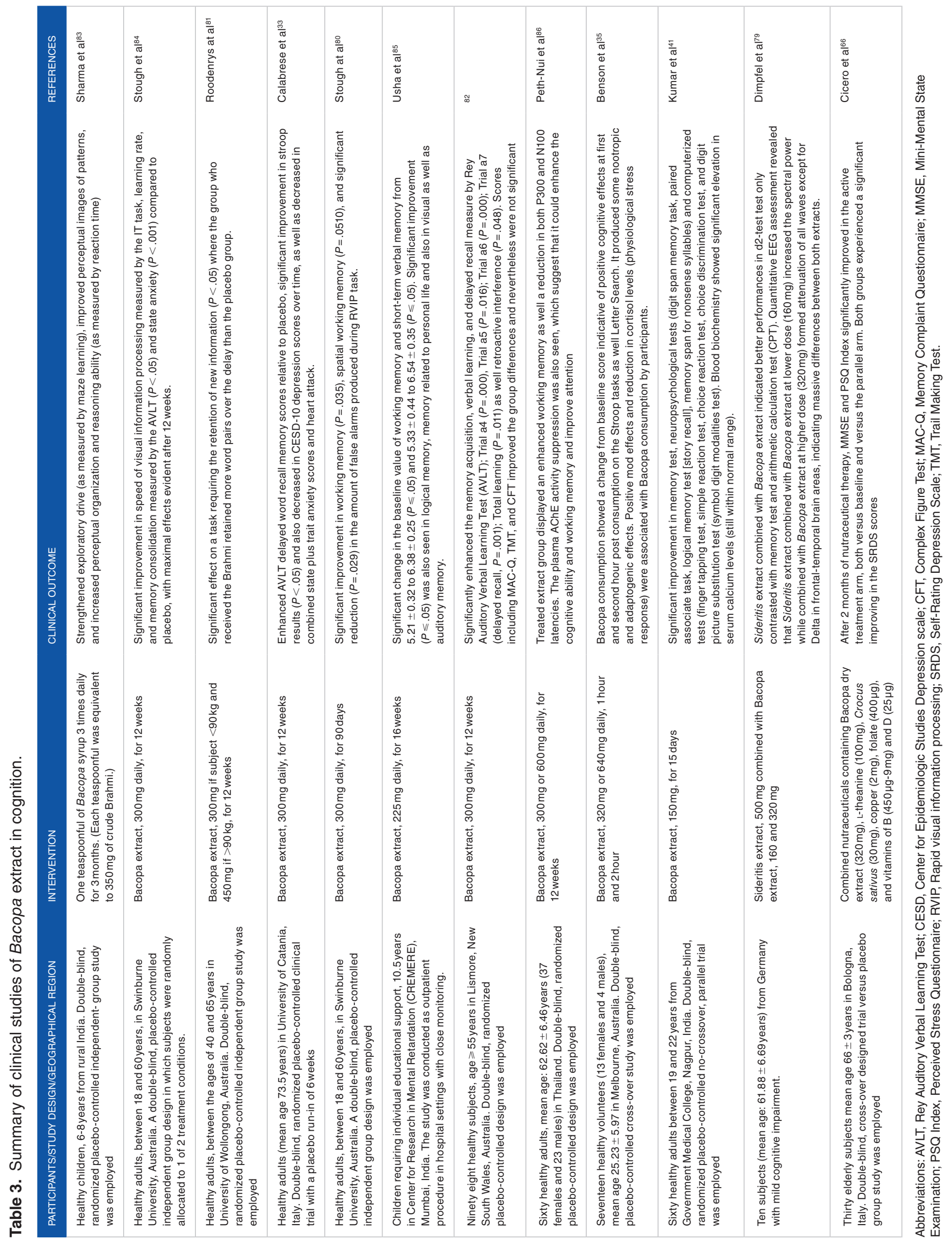


BME (300 mg/day) for 84 days in participants without dementia aged 65 years and above in University of Catania, Italy also showed improvement in their performance in a restraint recall and Stroop Task, that is, evaluating the capability to bypass unnecessary input. ${ }^{33}$ Moreover, in Lismore, New South Wales, Australia, the administration with $B$ monnieri $(300 \mathrm{mg} /$ day) in healthy volunteers over 55 years of age showed improvement in their oral learning, memory attainment, and suppressed recall. ${ }^{82}$

In another research done at Swinburne University of Technology, Melbourne, Australia using higher single dose in a double-blind, placebo-controlled trial among normal healthy subjects between the age of 18 and 44 years demonstrated an improved and preserved cognitive ability. ${ }^{36}$ Significant enhancement in prompt memory and response performance was also observed when Bacopa in the form of syrup (proportionate to $10 \mathrm{~g}$ dried Bacopa daily) was administered in 40 school children aged between 6 and 8 years for 90 days from rural India. ${ }^{83}$ The overall clinical trials in humans using BME are summarized in Table 3.

\section{Conclusions}

Many traditional plants especially $B$ monnieri have intricate mixtures of chemical compounds, which exhibit various pharmacological and biological activities. They have been used as traditional medicines and for anti-aging. According to the long-established hypothesis, plant compounds are able to maintain the fundamental vitality in the body and have various neuroprotective mechanisms that empower them to be used as part of our well-being. This review reveals the effective use of $B$ monnieri in cognition and neuroprotection and its phytoconstituents that can be used in novel drug discovery.

\section{Author Contributions}

ASAM, SV and PM designed the flow and wrote sub-sections of the manuscript. All other authors contributed to manuscript revision, proof reading and approval of the submitted version.

\section{ORCID iD}

Priya Madhavan (D) https://orcid.org/0000-0001-6714-1279

\section{REFERENCES}

1. Jadoopat R. Review of Alzheimer's disease treatment and potential future therapies. Annu Rev Chang Healthc. 2018;2.

2. Heneka MT, O'Banion MK. Inflammatory processes in Alzheimer's disease. $J$ Neuroimmunol. 2007;184:69-91.

3. Singh M, Murthy V, Ramassamy C. Modulation of hydrogen peroxide and acrolein-induced oxidative stress, mitochondrial dysfunctions and redox regulated pathways by the Bacopa monniera extract: potential implication in Alzheimer's disease. J Alzheimers Dis. 2010;21:229-247.

4. Bertram L, Lill CM, Tanzi RE. The genetics of Alzheimer disease: back to the future. Neuron. 2010;68:270-281.

5. Polidori MC, Pientka L, Mecocci P. A review of the major vascular risk factors related to Alzheimer's disease. J Alzheimers Dis. 2012;32:521-530.

6. Calabrese V, Butterfield DA, Stella A. Nutritional antioxidants and the heme oxygenase pathway of stress tolerance: novel targets for neuroprotection in Alzheimer's disease. Ital J Biochem. 2003;52:177-181.

7. Emilien G, Beyreuther K, Masters CL, Maloteaux J-M. Prospects for pharmacological intervention in Alzheimer disease. Arch Neurol. 2000;57:454-459.
8. Kontush A, Schekatolina S. Vitamin E in neurodegenerative disorders: Alzheimer's disease. Ann NY Acad Sci. 2004;1031:249-262.

9. Maity S, Nandy S, Mukherjee A, Dey A. Recent trends in drug discovery against Alzheimer's disease: use of natural products and nutraceuticals from botanicals. In: Ullah, MF, Ahmad, A, eds. Nutraceuticals and Natural Product Derivatives: Disease Prevention E Drug Discovery. Hoboken, NJ: John Wiley; 2019:237-278.

10. World Health Organization (WHO). Traditional medicine: fact sheet no. 134 https://apps.who.int/gb/ebwha/pdf_files/EB134/B134_24-en.pdf. Updated 2008.

11. Robinson MM, Zhang X. The World Medicines Situation 2011, Traditional Medicines: Global Situation, Issues and Challenges. Geneva, Switzerland: World Health Organization; 2011.

12. Sandhu DS, Heinrich M. The use of health foods, spices and other botanicals in the Sikh community in London. Phytother Res. 2005;19:633-642.

13. Satyavati G, Raina M, Sharma M. Indian Medicinal Plants. New Delhi, India: Indian Council of Medical Research; 1976:20-35.

14. Barrett SC, Strother JL. Taxonomy and natural history of Bacopa (Scrophulariaceae) in California. Syst Bot. 1978;3:408-419.

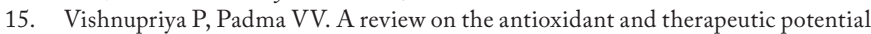
of Bacopa monnieri. React Oxygen Spec. 2017;3:111-120.

16. Anand T, Prakash KB, Pandareesh M, Khanum F. Development of bacoside enriched date syrup juice and its evaluation for physical endurance. $J$ Food $S c i$ Technol. 2014;51:4026-4032.

17. Blazquez-Sanchez MT, de Matos AM, Rauter AP. Exploring anti-prion glycobased and aromatic scaffolds: a chemical strategy for the quality of life. Molecules. 2017;22:864

18. Rauf K, Subhan F, Al-Othman A, Khan I, Zarrelli A, Shah M. Preclinical profile of bacopasides from Bacopa monnieri (BM) as an emerging class of therapeutics for management of chronic pains. Curr Med Chem. 2013;20:1028-1037.

19. Deepak M, Amit A. The need for establishing identities of "bacoside A and B," the putative major bioactive saponins of Indian medicinal plant Bacopa monnieri. Phytomedicine. 2004;11:264-268.

20. Kapoor R, Srivastava S, Kakkar P. Bacopa monnieri modulates antioxidant responses in brain and kidney of diabetic rats. Environ Toxicol Pharmacol. 2009;27:62-69.

21. Deepak M, Sangli G, Arun P, Amit A. Quantitative determination of the major saponin mixture bacoside A in Bacopa monnieri by HPLC. Phytochem Anal. 2005;16:24-29.

22. Saraf MK, Prabhakar S, Khanduja KL, Anand A. Bacopa monniera attenuates scopolamine-induced impairment of spatial memory in mice. Evid Based Complement Alternat Med. 2011;2011:236186.

23. Mukherjee S, Dugad S, Bhandare R, et al. Evaluation of comparative free-radical quenching potential of Brahmi (Bacopa monnieri) and Mandookparni (Centella asiatica). Ayu. 2011;32:258-264.

24. Holcomb LA, Dhanasekaran M, Hitt AR, Young KA, Riggs M, Manyam BV. Bacopa monniera extract reduces amyloid levels in PSAPP mice. J Alzheimers Dis. 2006;9:243-251.

25. Limpeanchob N, Jaipan S, Rattanakaruna S, Phrompittayarat W, Ingkaninan K. Neuroprotective effect of Bacopa monnieri on beta-amyloid-induced cell death in primary cortical culture. J Ethnopharmacol. 2008;120:112-117.

26. Rajan KE, Preethi J, Singh HK. Molecular and functional characterization of Bacopa monniera: a retrospective review. Evid Based Complement Alternat Med. 2015;2015:945217.

27. Chakravarty AK, Sarkar T, Masuda K, Shiojima K, Nakane T, Kawahara N. Bacopaside I and II: two pseudojujubogenin glycosides from Bacopa monniera. Phytochemistry. 2001;58:553-556.

28. Pardridge WM. Blood-brain barrier biology and methodology. J Neurovirol. 1999;5:556-569.

29. De K, Chandra S, Misra M. Evaluation of the biological effect of brahmi (Bacopa monnieri Linn) extract on the biodistribution of technetium-99m radiopharmaceuticals. Life Sci J. 2008;5:45-49.

30. Watkins PB. The barrier function of CYP3A4 and P-glycoprotein in the small bowel. Adv Drug Deliv Rev. 1997;27:161-170.

31. Singh R, Panduri J, Kumar D, et al. Evaluation of memory enhancing clinically available standardized extract of Bacopa monniera on P-glycoprotein and cytochrome P450 3A in Sprague-Dawley rats. PLoS ONE. 2013;8:e72517.

32. Barbhaiya H, Desai R, Saxena V, et al. Efficacy and tolerability of BacoMind on memory improvement in elderly participants-a double blind placebo controlled study. J Pharmacol Toxicol. 2008;3:425-434.

33. Calabrese C, Gregory WL, Leo M, Kraemer D, Bone K, Oken B. Effects of a standardized Bacopa monnieri extract on cognitive performance, anxiety, and depression in the elderly: a randomized, double-blind, placebo-controlled trial. $J$ Altern Complement Med. 2008;14:707-713.

34. Stough C, Scholey A, Cropley V, et al. Examining the cognitive effects of a special extract of Bacopa monniera (CDRI08: Keenmnd): a review of ten years of research at Swinburne University. J Pharm Pharm Sci. 2013;16:254-258.

35. Benson S, Downey LA, Stough C, Wetherell M, Zangara A, Scholey A. An acute, double-blind, placebo-controlled cross-over study of $320 \mathrm{mg}$ and $640 \mathrm{mg}$ 
doses of Bacopa monnieri (CDRI 08) on multitasking stress reactivity and mood. Phytother Res. 2014;28:551-559.

36. Downey LA, Kean J, Nemeh F, et al. An acute, double-blind, placebo-controlled crossover study of $320 \mathrm{mg}$ and $640 \mathrm{mg}$ doses of a special extract of Bacopa monnieri (CDRI 08) on sustained cognitive performance. Phytother Res. 2013;27:1407-1413.

37. Preethi J, Singh HK, Rajan KE. Possible involvement of standardized Bacopa monniera extract (CDRI-08) in epigenetic regulation of reelin and brain-derived neurotrophic factor to enhance memory. Front Pharmacol. 2016;7:166.

38. Rai R, Singh HK, Prasad S. A special extract of Bacopa monnieri (CDRI-08) restores learning and memory by upregulating expression of the NMDA receptor subunit GluN2B in the brain of scopolamine-induced amnesic mice. Evid Based Complement Alternat Med. 2015;2015:254303.

39. Goswami S, Saoji A, Kumar N, Thawani V, Tiwari M, Thawani M. Effect of Bacopa monnieri on cognitive functions in Alzheimer's disease patients. Int $J$ Collaborat Res Int Med Public Health. 2011;3:285-293.

40. Hingorani L, Patel S, Ebersole B. Sustained cognitive effects and safety of HPLC-standardized Bacopa monnieri extract: a randomized, placebo controlled clinical trial. Planta Medica. 2012;78:PH22.

41. Kumar N, Abichandani L, Thawani V, Gharpure K, Naidu M, Venkat Ramana G. Efficacy of standardized extract of Bacopa monnieri (Bacognize ${ }^{\circledR}$ ) on cognitive functions of medical students: a six-week, randomized placebo-controlled trial. Evid Based Complement Alternat Med. 2016;2016:4103423.

42. Thakkar VT, Deshmukh A, Hingorani L, et al. Development and optimization of dispersible tablet of Bacopa monnieri with improved functionality for memory enhancement. J Pharm Bioallied Sci. 2017;9:208-215.

43. Malishev R, Shaham-Niv S, Nandi S, Kolusheva S, Gazit E, Jelinek R. Bacoside$A$, an Indian traditional-medicine substance, inhibits $\beta$-amyloid cytotoxicity, fibrillation, and membrane interactions. ACS Chem Neurosci. 2017;8:884-891.

44. Farooqui AA, Farooqui T. Contribution of diabetes and metabolic syndrome in the pathogenesis of Alzheimer's disease. In: Farooqui, T, Farooqui, AA, eds. Role of the Mediterranean Diet in the Brain and Neurodegenerative Diseases. London, England: Elsevier; 2018:301-316.

45. Chaudhari KS, Tiwari NR, Tiwari RR, Sharma RS. Neurocognitive effect of nootropic drug brahmi (Bacopa monnieri) in Alzheimer's disease. Ann Neurosci. 2017;24:111-122.

46. Cheignon C, Tomas M, Bonnefont-Rousselot D, Faller P, Hureau C, Collin F. Oxidative stress and the amyloid beta peptide in Alzheimer's disease. Redox Biology. 2018;14:450-464.

47. Manoharan S, Guillemin GJ, Abiramasundari RS, Essa MM, Akbar M, Akbar $\mathrm{MD}$. The role of reactive oxygen species in the pathogenesis of Alzheimer's disease, Parkinson's disease, and Huntington's disease: a mini review. Oxid Med Cell Longev. 2016;2016:8590578.

48. Magalingam KB, Radhakrishnan A, Ping NS, Haleagrahara N. Current concepts of neurodegenerative mechanisms in Alzheimer's disease. Biomed Res Int. 2018;2018:3740461.

49. Flannery PJ, Trushina E. Mitochondrial dysfunction in Alzheimer's disease and progress in mitochondria-targeted therapeutics [published online ahead of print June 8, 2019]. Curr Behav Neurosci Rep. doi:10.1007/s40473-019-00179-0.

50. Huang W, Zhang X, Chen W. Role of oxidative stress in Alzheimer's disease. Biomed Rep. 2016;4:519-522.

51. Mecocci P, Boccardi V, Cecchetti R, et al. A long journey into aging, brain aging, and Alzheimer's disease following the oxidative stress tracks. J Alzheimers Dis. 2018;62:1319-1335.

52. Ramesh S, Govindarajulu M, Jones E, Suppiramaniam V, Moore T, Dhanasekaran M. Mitochondrial dysfunction and the role of Mitophagy in Alzheimer's disease. https://pdfs.semanticscholar.org/548a/b1df84b2168d94bb851644d90e 695523443a.pdf. Updated 2018.

53. Bhatia S, Kim WS, Shepherd CE, Halliday GM. Apolipoprotein D upregulation in Alzheimer's disease but not frontotemporal dementia. J Mol Neurosci. 2019;67:125-132.

54. Massaccesi L, Galliera E, Galimberti D, et al. Lag-time in Alzheimer's disease patients: a potential plasmatic oxidative stress marker associated with ApoE4 isoform. Immun Ageing. 2019;16:7.

55. Nikseresht S, Bush AI, Ayton S. Treating Alzheimer's disease by targeting iron [published online ahead of print February 2019]. Br J Pharmacol. doi:10.1111/ bph.14567.

56. Russo A, Borrelli F, Campisi A, Acquaviva R, Raciti G, Vanella A. Nitric oxiderelated toxicity in cultured astrocytes: effect of Bacopa monniera. Life Sci. 2003;73:1517-1526

57. Tripathi YB, Chaurasia S, Tripathi E, Upadhyay A, Dubey GP. Bacopa monniera Linn. As an antioxidant: mechanism of action. Indian J Exp Biol. 1996;34:523-526.

58. Chowdhuri DK, Parmar D, Kakkar P, Shukla R, Seth P, Srimal R. Antistress effects of bacosides of Bacopa monnieri: modulation of Hsp70 expression, superoxide dismutase and cytochrome P450 activity in rat brain. Phytother Res. 2002;16:639-645
59. Thomas RB, Joy S, Ajayan M, Paulose C. Neuroprotective potential of Bacopa monnieri and Bacoside A against dopamine receptor dysfunction in the cerebral cortex of neonatal hypoglycaemic rats. Cell Mol Neurobiol. 2013;33:1065-1074.

60. Singh H, Dhawan B. Drugs affecting learning and memory. Lect Neuro. 1992;1:189-207.

61. Batarseh YS, Duong Q-V, Mousa YM, A1 Rihani SB, Elfakhri K, Kaddoumi A. Amyloid- $\beta$ and astrocytes interplay in amyloid- $\beta$ related disorders. Int J Mol Sci. 2016;17:338.

62. Selkoe DJ, Hardy J. The amyloid hypothesis of Alzheimer's disease at 25 years. EMBO Mol Med. 2016;8:595-608.

63. Khan UA, Liu L, Provenzano FA, et al. Molecular drivers and cortical spread of lateral entorhinal cortex dysfunction in preclinical Alzheimer's disease. Nat Neurosci. 2014;17:304-311.

64. Nussbaum JM, Schilling S, Cynis $H$, et al. Prion-like behaviour and taudependent cytotoxicity of pyroglutamylated amyloid- $\beta$. Nature. 2012;485: 651-655.

65. Malishev R, Nandi S, Kolusheva S, Shaham-Niv S, Gazit E, Jelinek R. Bacoside-A, an anti-amyloid natural substance, inhibits membrane disruption by the amyloidogenic determinant of prion protein through accelerating fibril formation. Biochim Biophys Acta. 2016;1858:2208-2214.

66. Cicero A, Bove M, Colletti A, et al. Short-term impact of a combined nutraceutical on cognitive function, perceived stress and depression in young elderly with cognitive impairment: a pilot, double-blind, randomized clinical trial. J Prev Alz Dis. 2016;4:12-15.

67. Thippeswamy AH, Rafiq M, Viswantha GL, Kavya KJ, Anturlikar SD, Patki PS. Evaluation of Bacopa monniera for its synergistic activity with rivastigmine in reversing aluminum-induced memory loss and learning deficit in rats. $J A c u-$ punct Meridian Stud. 2013;6:208-213.

68. Das A, Shanker G, Nath C, Pal R, Singh S, Singh HK. A comparative study in rodents of standardized extracts of Bacopa monniera and Ginkgo biloba: anticholinesterase and cognitive enhancing activities. Pharmacol Biochem Behav. 2002;73:893-900.

69. Uabundit N, Wattanathorn J, Mucimapura S, Ingkaninan K. Cognitive enhancement and neuroprotective effects of Bacopa monnieri in Alzheimer's disease model. J Ethnopharmacol. 2010;127:26-31.

70. Jyoti A, Sethi P, Sharma D. Bacopa monniera prevents from aluminium neurotoxicity in the cerebral cortex of rat brain. J Ethnopharmacol. 2007;111:56-62.

71. Khan MB, Ahmad M, Ahmad S, et al. Bacopa monniera ameliorates cognitive impairment and neurodegeneration induced by intracerebroventricular-streptozotocin in rat: behavioral, biochemical, immunohistochemical and histopathological evidences. Metab Brain Dis. 2015;30:115-127.

72. Kunte KB, Kuna Y. Neuroprotective effect of Bacopa monniera on memory deficits and ATPase system in Alzheimer's disease (AD) induced mice. J Sci Innov Res. 2013;2:719-735.

73. Dwivedi S, Nagarajan R, Hanif K, Siddiqui HH, Nath C, Shukla R. Standardized extract of Bacopa monniera attenuates okadaic acid induced memory dysfunction in rats: effect on Nrf2 pathway. Evid Based Complement Alternat Med. 2013;2013:294501.

74. Rastogi M, Ojha RP, Prabu P, Devi BP, Agrawal A, Dubey G. Prevention of age-associated neurodegeneration and promotion of healthy brain ageing in female Wistar rats by long term use of bacosides. Biogerontology. 2012;13: 183-195.

75. Jose S, Sowmya S, Cinu T, Aleykutty N, Thomas S, Souto E. Surface modified PLGA nanoparticles for brain targeting of Bacoside-A. Eur J Pharm Sci. 2014;63:29-35

76. Pandareesh M, Anand T. Neuromodulatory propensity of Bacopa monniera against scopolamine-induced cytotoxicity in PC12 cells via down-regulation of $\mathrm{AChE}$ and up-regulation of BDNF and muscarnic-1 receptor expression. Cell Mol Neurobiol. 2013;33:875-884

77. Yamchuen P, Chaiwiang N, Lapphanichayakool P, Ingkaninan K, Limpeanchob N. Neuroprotective effect of Bacopa Monnieri extract on oxidized low density lipoprotein-induced neurotoxicity in SH-SY5Y neuroblastoma cells. Thai $J$ Pharm. 2017;39:5-18.

78. Habbu P, Madagundi S, Kulkarni R, Jadav S, Vanakudri R, Kulkarni V. Preparation and evaluation of Bacopa-phospholipid complex for antiamnesic activity in rodents. Drug Invention Today. 2013;5:13-21.

79. Dimpfel W, Schombert L, Biller A. Psychophysiological effects of Sideritis and Bacopa extract and three combinations thereof-a quantitative EEG study in subjects suffering from mild cognitive impairment (MCI). Advances in Alzheimer's Disease. 2016;5:1-22.

80. Stough C, Downey LA, Lloyd J, et al. Examining the nootropic effects of a special extract of Bacopa monniera on human cognitive functioning: 90 day doubleblind placebo-controlled randomized trial. Phytother Res. 2008;22:1629-1634.

81. Roodenrys S, Booth D, Bulzomi S, Phipps A, Micallef C, Smoker J. Chronic effects of Brahmi (Bacopa monnieri) on human memory. Neuropsychopharmacology. 2002;27:279-281. 
82. Morgan A, Stevens J. Does Bacopa monnieri improve memory performance in older persons? Results of a randomized, placebo-controlled, double-blind trial. $J$ Altern Complement Med. 2010;16:753-759.

83. Sharma R, Chaturvedi C, Tewari P. Efficacy of Bacopa monniera in revitalizing intellectual functions in children. J Res Edu Ind Med. 1987;1:12.

84. Stough C, Lloyd J, Clarke J, et al. The chronic effects of an extract of Bacopa monniera (Brahmi) on cognitive function in healthy human subjects. Psychopharmacology. 2001;156:481-484.
85. Usha $\mathrm{P}$, Wasim $\mathrm{P}$, Joshua J, et al. BacoMind ${ }^{\oplus}$ : a cognitive enhancer in children requiring individual education programme. J Pharmacol Toxicol. 2008;3: 302-310.

86. Peth-Nui T, Wattanathorn J, Muchimapura S, et al. Effects of 12-week Bacopa monnieri consumption on attention, cognitive processing, working memory, and functions of both cholinergic and monoaminergic systems in healthy elderly volunteers. Evid Based Complement Alternat Med. 2012;2012: 606424 . 